Jurnal Satyagraha

Vol. 03, No. 02, Agustus 2020 - Januari 2021

ISSN : 2620-6358

http://ejournal.universitasmahendradatta.ac.id/index.php/satyagraha

\title{
KAJIAN ANALISIS JALUR DENGAN STRUCTURAL EQUATION MODELING (SEM) SMART-PLS 3.0
}

\author{
I Made Anom Arya Pering \\ Program Studi Manajemen, Fakultas Ekonomi - Universitas Mahendradatta \\ Jln. Ken Arok 12, Peguyangan, Denpasar Utara - Bali. 80115 \\ E-mail : anomaryapering@gmail.com \\ aryaperinganom@gmail.com
}

\section{Abstract}

Study on Path Analysis using Structural Equation Modeling (SEM) Smart Partial Least Squares (PLS) software version 3.0 with the aim of testing the Impact or Effect of Training on Employee Performance and Organizational Performance, whether it has a significant effect.

The analysis results obtained are:

First, the Effect of Employee Performance on Organizational Performance. The $t$-statistic value of 2.721 and the significance (t-table significance of $5 \%=$ 1.96) because the t-statistic value of 2.721 is greater $(>)$ than the t-table of 1.96 , Employee Performance has a "significant" effect on Organizational Performance.

Second, the Effect of Training (Training) on Employee Performance

The $t$-statistic value of 2.688 significance ( $t$-table significance of $5 \%=1.96$ ) because the t-statistic value of 2.688 is greater $(>)$ than the t-table of 1.96 , the Training has a "significant" effect on Employee Performance.

Third, the Effect of Training (Training) on Organizational Performance The t-statistic value of 0.338 significance ( $t$-table significance of $5 \%=1.96$ ) because the t-statistic value of 0.338 is smaller $(<)$ than t-table 1.96, the "insignificant" Training has a direct effect on Organizational Performance.

Keywords: Path Analysis, SEM, Smart-PLS 3.0

\section{Abstrak}

Kajian Analisis Jalur (Path Analysis) dengan menggunakan model persamaan struktural atau Structural Equation Modelling (SEM) software Smart Partial Least Squares (Smart-PLS) versi 3.0 dengan tujuan untuk menguji Dampak atau Pengaruh Pelatihan (Training) terhadap Kinerja Karyawan dan Kinerja Organisasi, apakah berpengaruh signifikan.

Hasil analisis yang diperoleh adalah :

Pertama, Pengaruh Kinerja Karyawan terhadap Kinerja Organisasi. Nilai tstatistik sebesar 2.721 dan signifikansi (t-tabel signifikansi $5 \%=1.96$ ) oleh karena nilai t-statistik 2.721 lebih besar ( $>$ ) dari t-tabel 1.96 maka Kinerja Karyawan berpengaruh "signifikan" terhadap Kinerja Organisasi.

Kedua, Pengaruh Pelatihan (Training) terhadap Kinerja Karyawan. Nilai tstatistik sebesar 2.688 signifikansi (t-tabel signifikansi $5 \%=1.96)$ oleh karena nilai t-statistik 2.688 lebih besar $(>)$ dari t-tabel 1.96 maka Pelatihan (Training) berpengaruh "signifikan" terhadap Kinerja Karyawan.

Ketiga, Pengaruh Pelatihan (Training) terhadap Kinerja Organisasi. Nilai tstatistik sebesar 0.338 signifikansi $(\mathrm{t}$-tabel signifikansi $5 \%=1.96)$ oleh karena 
Jurnal Satyagraha

Vol. 03, No. 02, Agustus 2020 - Januari 2021

ISSN : 2620-6358

http://ejournal.universitasmahendradatta.ac.id/index.php/satyagraha

nilai t-statistik 0.338 lebih kecil $(<)$ dari t-tabel 1.96 maka Pelatihan (Training) "tidak signifikan" berpengaruh langsung terhadap Kinerja Organisasi.

Kata kunci : Analisis Jalur, SEM, Smart-PLS 3.0

\section{PENDAHULUAN}

\section{Latar Belakang}

Bahwa para ahli metode menimbulkan kesulitan tersendiri penelitian mengelompokkan model dalam pengukurannya. Dalam persamaan struktural atau Structural sebuah riset yang melibatkan Equation Modelling (SEM) menjadi sejumlah variabel laten, dibutuhkan dua pendekatan. Pertama disebut sebagai Covariance Base SEM (CBSEM) dan kedua disebut sebagai

Variance Base SEM (VB-SEM) atau yang lebih dikenal dengan Partial Least Squares (PLS). Untuk melakukan analisa dengan menggunakan CB-SEM adalah dengan software AMOS, LISREL, sedangkan untuk VB-SEM atau (PLS) adalah software Smart-PLS, WarpPLS dan XLStat.

Model persamaan struktural atau Structural Equation Modelling (SEM) adalah alat analisis statistik yang populer saat ini. SEM oleh para ahli statistik, mencari metode untuk membuat model yang dapat menjelaskan hubungan di antara variabel-variabel. Persoalan timbul karena banyak variabel yang pula sejumlah indikator, dan antar variabel laten akan terdapat sejumlah hubungan. Sebagai gambaran awal, model kompleks semacam itu dapat disebut dengan sebuah model SEM. Analisis model semacam ini tidak dapat menggunakan alat-alat statistik tradisional seperti uji $t$, anova, korelasi, atau regresi berganda (Singgih Santoso, 2018: 1). Software yang digunakan adalah AMOS atau LISREL pada sebuah model yang kompleks dapat mudah diuji, baik hubungan indikator-indikator dengan konstruknya, atau hubungan antar konstruk. Bahwa SEM secara esensial menawarkan kemampuan untuk melakukan analisis jalur (path analysis) dengan variabel laten (Chin, 1998 pada Imam Ghozali, termasuk variabel laten yang 2014: 3). 
Jurnal Satyagraha

Vol. 03, No. 02, Agustus 2020 - Januari 2021

ISSN : 2620-6358

http://ejournal.universitasmahendradatta.ac.id/index.php/satyagraha

Bahwa Partial Least Squares

(PLS) merupakan metode analisis powerfull dan sering disebut juga sebagai soft modeling karena meniadakan asumsi-asumsi Ordinary Least Square (OLS) regresi, seperti data harus terdistribusi normal secara multivariate dan tidak adanya problem multikolonieritas antar variabel eksogen (Wold 1985 pada Imam Ghozali, 2014: 5). Pada kajian ini menggunakan SEM Partial Least Squares (PLS) software Smart-PLS 3.0

Bahwa analisis SEM Partial Least Squares (PLS) dengan software Smart-PLS 3.0 belum banyak digunakan oleh para peneliti khususnya mahasiswa dalam tugas akhir Skripsi. Kajian ini dapat digunakan sebagai panduan dalam rangka penyusunan skripsi. Kajian Analisis Jalur (Path Analysis) dengan mengambil objek penelitian Dampak Pelatihan (Training) terhadap Kinerja Karyawan dan Kinerja Organisasi, pada PT Hamsa Jaya Makmur Bali, dengan menggunakan SEM Partial Least
Squares (PLS) software Smart-PLS

versi 3.0

\section{Rumusan Masalah}

1. Apakah Pelatihan (Training)

memiliki pengaruh atau dampak

yang signifikan terhadap Kinerja

Karyawan?

2. Apakah Kinerja Karyawan memiliki

pengaruh atau dampak yang

signifikan terhadap Kinerja

Organisasi?

3. Apakah Training memiliki pengaruh atau dampak yang signifikan terhadap Kinerja Organisasi?

\section{Tujuan Penelitian}

Tujuan penelitian ini adalah untuk mengetahui Pelatihan (Training) mempunyai pengaruh atau dampak signifikan terhadap kinerja karyawan. Kinerja Karyawan mempunyai pengaruh atau dampak signifikan terhadap Kinerja Organisasi dan untuk mengetahui Pelatihan (Training) mempunyai pengaruh atau dampak signifikan terhadap Kinerja Organisasi. 
Jurnal Satyagraha

Vol. 03, No. 02, Agustus 2020 - Januari 2021

ISSN : 2620-6358

http://ejournal.universitasmahendradatta.ac.id/index.php/satyagraha

Tujuan Kajian Artikel

Tujuan kajian artikel adalah memberikan pengetahuan tentang analisis jalur (path analysis) pada para peneliti khususnya mahasiswa dalam menggunakan analisis SEM dengan software Smart-PLS 3.0

\section{KERANGKA TEORITIS}

Telah disebutkan di atas bahwa SEM secara esensial menawarkan kemampuan untuk melakukan analisis jalur (path analysis) dengan variabel laten. Pada penelitian ini kajian analisis jalur (path analysis) dengan objek penelitian Pengaruh atau dampak Pelatihan (Training) terhadap Kinerja Karyawan dan Kinerja Organisasi. Sebagai variabel independen (X) adalah Pelatihan (Training), dan variabel dependen (Y1) Kinerja Karyawan, serta variabel dependen (Y2) Kinerja Organisasi. Berkenaan dengan variavel dependen ada dua, maka digunakan analisis jalur dengan SEM software Smart-PLS versi 3.0
Manajemen Sumber Daya

\section{Manusia}

Menurut Hasibuan (2011: 10) manajemen sumber daya manusia adalah "ilmu dan seni mengatur hubungan dan peranan tenaga kerja agar efektif dan efisien membantu terwujudnya tujuan perusahaan, karyawan dan masyarakat". Sedangkan French dalam Gary Dessler (2009:2) menyatakan "manajemen sumber daya manusia adalah sebuah konsep dan teknik yang dibutuhkan untuk menangani aspek personalia atau sumber daya manusia dari sebuah posisi manajerial, seperti rekrutmen, seleksi, pelatihan, pemberian imbalan, penilaian dan semua kegiatan lain yang selama ini dikenal."

\section{Pelatihan (Training) \\ Menurut Sutrisno (2009: 109) "Pelatihan dimaksudkan untuk melengkapi pegawai dengan ketrampilan cara-cara yang tepat untuk menggunakan peralatan kerja. Untuk itu latihan kerja diperlukan bukan saja sebagai perlengkapan}


Jurnal Satyagraha

Vol. 03, No. 02, Agustus 2020 - Januari 2021

ISSN : 2620-6358

http://ejournal.universitasmahendradatta.ac.id/index.php/satyagraha

akan tetapi sekaligus untuk pelatihan pun harus update agar si memberikan dasar-dasar peserta dapat dapat memahami pengetahuan". masalah yang terjadi pada kondisi

Indikator-indikator pelatihan

menurut Anwar Prabu

Mangkunegara (2007) diantaranya:

1. Instruktur

Mengingat pelatih umumnya berorientasi pada peningkatan skill, maka para pelatih yang dipilih untuk memberikan materi pelatihan harus benar-benar memiliki kualifikasi yang memadai sesuai bidangnya, personal dan kompeten, selain itu pendidikan intruktur pun harus benar-benar baik untuk melakukan pelatihan.

2. Peserta

Peserta pelatihan tentunya harus diseleksi berdasarkan persyaratan tertentu dan kualifikasi yang sesuai, selain itu peserta pelatihan juga harus memiliki semangat yang tinggi untuk mengikuti pelatihan.

3. Materi

Pelatihan sumber daya manusia merupakan materi atau kurikulum yang sesuai dengan tujuan pelatihan sumber daya manusia yang hendak dicapai oleh perusahaan dan materi yang sekarang.

4. Metode

Metode pelatihan akan lebih menjamin berlangsungnya kegiatan pelatihan sumber daya manusia yang efektif apabila sesuai dengan jenis materi dan komponen peserta pelatihan.

5. Tujuan

Pelatihan merupakan tujuan yang ditentukan, khususnya terkait dengan penyusunan rencana aksi (action play) dan penetapan sasaran, serta hasil yang diharapkan dari pelatihan yang akan diselenggarakan, selain itu tujuan pelatihan pula harus disosialisasikan sebelumnya pada para peserta agar peserta dapat memahami pelatihan tersebut.

6. Sasaran

Sasaran pelatihan harus ditentukan dengan kriteria yang terinci dan terukur (measurable).

\section{Kinerja Karyawan}

Menurut Dessler (2009)

Kinerja karyawan adalah prestasi 
Jurnal Satyagraha

Vol. 03, No. 02, Agustus 2020 - Januari 2021

ISSN : 2620-6358

http://ejournal.universitasmahendradatta.ac.id/index.php/satyagraha

aktual karyawan dibandingkan

dengan prestasi yang diharapkan dari

karyawan. Prestasi kerja yang

diharapkan adalah prestasi standar

yang disusun sebagai acuan sehingga

dapat melihat karyawan sesuai

dengan posisinya dibandingkan

dengan standar yang dibuat. Selain

itu dapat juga dilihat kinerja dari

karyawan tersebut terhadap

karyawan lainnya.

Menurut Mathis dan Jackson

(2006: 378) Kinerja karyawan yang umum untuk kebanyakan pekerjaan meliputi indikator sebagai berikut :

[1]Kuantitas

Jumlah yang harus diselesaikan atau dicapai. Pengukuran kualitatif melibatkan perhitungan keluaran dari proses atau pelaksanaan kegiatan. Ini berkaitan dengan jumlah keluaran yang dihasilkan.

[2]Kualitas

Mutu yang harus dihasilkan (baik tidaknya). Pengukuran kualitatif keluaran mencerminkan pengukuran "tingkat kepuasan" yaitu seberapa baik pe-nyelesaiannya. Ini berkaitan dengan bentuk keluaran.
[3]Keandalan

Keandalan adalah kemampuan untuk melakukan pekerjaan yang diisyaratkan dengan supervise minimum.

[4]Kehadiran atau absensi

Tingkat kehadiran merupakan sesuatu yang menjadi tolak ukur sebuah perusahaan dalam mengetahui tingkat partisipasi karyawan pada perusahaan.

[5]Kemampuan bekerja sama

Kemampuan bekerja sama dapat menciptakan kekompakan sehingga dapat meningkatkan rasa kerja sama antar karyawan.

\section{Kinerja Organisasi}

Menurut Wibowo dalam Pasolong (2010: 176) kinerja organisasi me-rupakan efektivitas organisasi secara menyeluruh untuk kebutuhan yang ditetapkan dari setiap kelompok yang berkenaan melalui usaha-usaha yang sistematik dan meningkatkan kemampuan organisasi secara terus menerus untuk mencapai kebutuhannya secara efektif. 
Jurnal Satyagraha

Vol. 03, No. 02, Agustus 2020 - Januari 2021

ISSN : 2620-6358

http://ejournal.universitasmahendradatta.ac.id/index.php/satyagraha

Indikator kinerja organisasi penelitian, dimana rumusan masalah menurut (Sinambela, 2012: 192), penelitian telah dinyatakan dalam adalah sebagai berikut :

bentuk kalimat pertanyaan.

[1] Kebijakan, untuk membantu Dikatakan sementara, karena pembuatan maupun jawaban yang diberikan baru pengimplementasian kebijakan tersebut.

[2] Perencanaan dan penganggaran, untuk membantu perencanaan dan peng-anggaran atas jasa yang diberikan dan untuk memonitor perubahan terhadap rencana.

[3] Kualitas, untuk memajukan standarisasi atas jasa yang diberikan maupun keefektifan organisasi.

[4] Kehematan, untuk meninjau ulang pendistribusian dan keefektifan penggunaan sumber daya.

[5] Keadilan, untuk meyakini adanya distribusi yang adil dan dilayani semua masyarakat.

[6] Pertanggung jawaban, untuk meningkatkan pengendalian dan mempengaruhi pembuatan keputusan

\section{Hipotesis}

$$
\text { Menurut Sugiyono }
$$
mendeskripsikan hipotesis merupakan jawaban sementara terhadap rumusan masalah didasarkan pada teori yang relevan, belum didasarkan pada fakta-fakta empiris yang diperoleh melalui pengumpulan data.

Hipotesis dalam penelitian ini adalah :

1. Pelatihan (Training) berpengaruh signifikan terhadap Kinerja Karyawan.

2. Kinerja Karyawan berpengaruh signifikan terhadap Kinerja Organisasi.

3. Pelatihan (Training) berpengaruh signifikan terhadap Kinerja Organisasi.

\section{METODE PENELITIAN}

\section{Operasional Variabel Penelitian}

Menentukan Operasional Variabel Penelitian Pengaruh atau Dampak Pelatihan (Training) terhadap Kinerja Karyawan dan Kinerja Organisasi :

1. Sebagai Variabel Independen (X) adalah Pelatihan (Training) pada 
Jurnal Satyagraha

Vol. 03, No. 02, Agustus 2020 - Januari 2021

ISSN : 2620-6358

http://ejournal.universitasmahendradatta.ac.id/index.php/satyagraha

PLS disebut Variabel Laten 1 dengan

indikator-indikator $\quad$ : $\quad\left(\mathrm{X}_{-} 1\right)$

Instruktur, (X_2) Peserta, (X_3)

Materi, (X_4) Metode, (X_5)

Tujuan, (X_6) Sasaran.

2. Sebagai Variabel Dependen (Y1) adalah Kinerja Karyawan pada PLS disebut Variabel Laten 2 dengan indikator-indikator $\quad$ : $\quad(\mathrm{Y} 1$ 1 1$)$ Kuantitas, (Y1_2) Kualitas, (Y1_3) Keandalan, (Y1_4) Kehadiran atau absensi, (Y1_5) Kemampuan bekerja sama.

3. Sebagai Variabel Dependen (Y2) adalah Kinerja Organisasi, disebut Variabel Laten 3 dengan indikatorindikator: (Y2_1) Kebijakan, (Y2_2) Perencanaan dan penganggaran, (Y2_3) Kualitas, (Y2_4) Kehematan, (Y2_5) Keadilan, dan (Y2_6) Pertanggung jawaban.

\section{Populasi dan Sampel Penelitian}

Menetapkan sampel penelitian, sejumlah 35 karyawan dari jumlah populasi 35 orang, dan jawaban kuesioner menggunakan skala Likert.

\section{Teknik Analisis Data}

Teknik Analisis Data pada PLS dengan software Smart PLS versi 3.0 dengan tahapan sebagai berikut:

1. Pengujian Outer Model, menspesifikasi hubungan antar variabel laten dengan indikatorindikatornya, atau dapat dikatakan bahwa outer model mendefinisikan bagaimana setiap indikator berhubungan dengan variabel latennya. Uji yang dilakukan pada outer model, yaitu sebagai berikut :

[1] Convergent Validity. Nilai convergen validity adalah nilai loading faktor pada variabel laten dengan indikatorindikatornya. Nilai yang diharapkan $>0.7$

[2] Discriminant Validity. Nilai ini merupakan nilai cross loading faktor yang berguna untuk mengetahui apakah konstruk memiliki diskriminan yang memadai yaitu dengan cara membandingkan nilai loading pada konstruk yang dituju harus lebih besar dibandingkan dengan nilai loading dengan konstruk yang lain.

[3] Average Variance Extracted (AVE). Nilai AVE yang diharapkan $>0.5$ 
Jurnal Satyagraha

Vol. 03, No. 02, Agustus 2020 - Januari 2021

ISSN : 2620-6358

http://ejournal.universitasmahendradatta.ac.id/index.php/satyagraha

[4] Composite Reliability. Data yang memiliki composite reliability $>0.7$ mempunyai reliabilitas yang tinggi. Cronbach Alpha. Uji reliabilitas diperkuat dengan Cronbach Alpha. Nilai diharapkan $>0.7$ untuk semua konstruk.

2. Pengukuran Model Struktural (Inner Model)

a) Pengujian terhadap model struktural (Inner Model) dilakukan dengan melihat nilai R-Square yang merupakan uji goodness-fit model.

b) Uji yang kedua adalah melihat signifikansi dengan melihat nilai koefisien parameter dan nilai signifikansi $t$ statistik pada Algorithm Boostrapping report Path Coefficients. Nilai t-statistik lebih besar dari t-tabel dan signifikansi (t-tabel signifikansi 5\% $=1.96$ )

\section{HASIL UJI HIPOTESIS}

Hasil pengujian hipotesis :

1. Data dalam format .csv (comma, separated, value).

2. Mendesain model dan menginput data.

3. Analisis dengan PLS Algorithm dan Hasil. a. Pengukuran Outer Model

(1) Convergent validity, dari pengukuran model dengan indikator refleksif dapat dilihat dari korelasi antara score item/indikator dengan score konstruknya. Indikator dinyatakan reliabel jika memiliki nilai korelasi di atas 0.70

Hasil desain model dan input data serta hasil PLS Algorithm sebagai gambar model di bawah ini. 
Jurnal Satyagraha

Vol. 03, No. 02, Agustus 2020 - Januari 2021

ISSN : 2620-6358

http://ejournal.universitasmahendradatta.ac.id/index.php/satyagraha

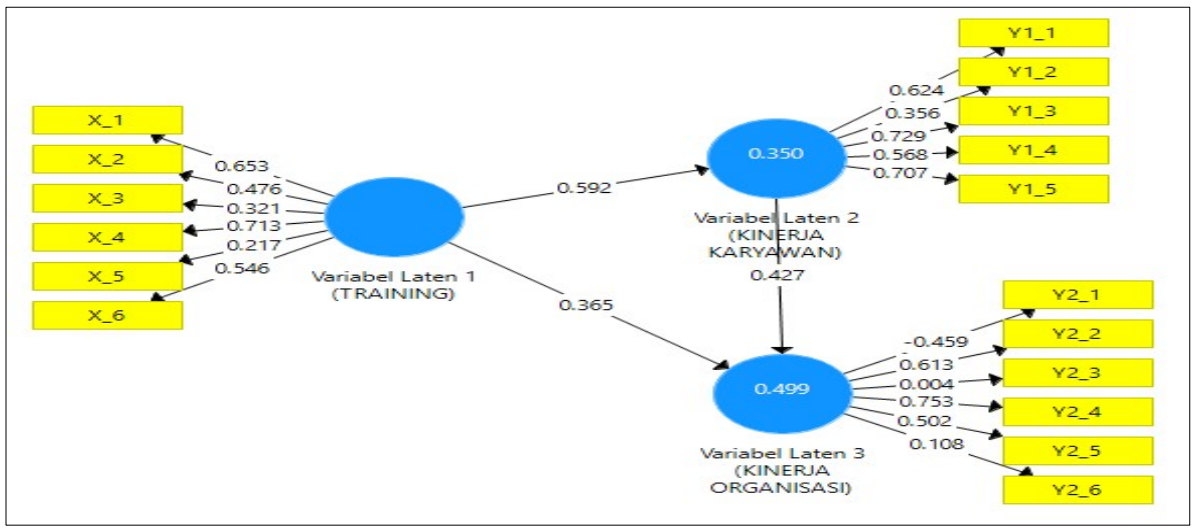

Hasil desain model dan input data serta hasil PLS Algorithm Dampak Pelatihan (Training) terhadap Kinerja Karyawan dan Kinerja Organisasi

Dari gambar model terdapat item X_1, X_2, $X \_3, X \_5, X \_6$ dan item Y1_1, Y1_2, Y1_4, serta item Y2_1, Y2_2, Y2_3, Y2_5, Y2_6 memiliki nilai faktor loading di bawah 0,7 oleh karena itu item tersebut harus dihapus dari model.

Hasil output korelasi antara indikator dengan konstruknya sebagai Outer Loadings di bawah ini.

Tabel 1 Outer Loadings

Indikator-indikator dari Variabel-variabel Laten

\begin{tabular}{|c|c|c|c|c|}
\hline \multirow{2}{*}{\multicolumn{2}{|c|}{ 四 Matrix }} & & & \\
\hline & & KINERUA KARY... & KINERUA ORGA... & TRAINING \\
\hline$x_{-} 1$ & & & & 0.653 \\
\hline$x \_2$ & & & & 0.476 \\
\hline$x_{-3}$ & & & & 0.321 \\
\hline$x \_4$ & & & & 0.713 \\
\hline$x \_5$ & & & & 0.217 \\
\hline$x \_6$ & & & & 0.546 \\
\hline$Y 1$ 1 & & 0.624 & & \\
\hline$\times 1 \_2$ & & 0.356 & & \\
\hline$\Upsilon 113$ & & 0.729 & & \\
\hline$Y 1 / 4$ & & 0.568 & & \\
\hline Y1_S & & 0.707 & & \\
\hline$x 2-1$ & & & -0.459 & \\
\hline$r 2 \_2$ & & & 0.613 & \\
\hline$r 2 \_3$ & & & 0.004 & \\
\hline$r 2 \_4$ & & & 0.753 & \\
\hline rz_s & & & 0.502 & \\
\hline Y2_6 & & & 0.108 & \\
\hline
\end{tabular}


Jurnal Satyagraha

Vol. 03, No. 02, Agustus 2020 - Januari 2021

ISSN : 2620-6358

http://ejournal.universitasmahendradatta.ac.id/index.php/satyagraha

\begin{tabular}{lr}
\multicolumn{1}{c}{ Berdasarkan outer } & $\begin{array}{r}\text { indikator yang memiliki nilai } \\
\text { yang kurang dari } 0.70 \\
\text { loading di atas, maka indikator }\end{array}$ \\
dengan nilai yang merwarna & Model berikutnya yang \\
merah dikeluarkan dari model, & memiliki nilai faktor loading di \\
karena memiliki loading & atas 0,7 sebagai gambar di \\
kurang dari 0.70 Model di re- & bawah ini, serta outer loading- \\
estimasi kembali dengan & nya. \\
mengeluarkan indikator- &
\end{tabular}

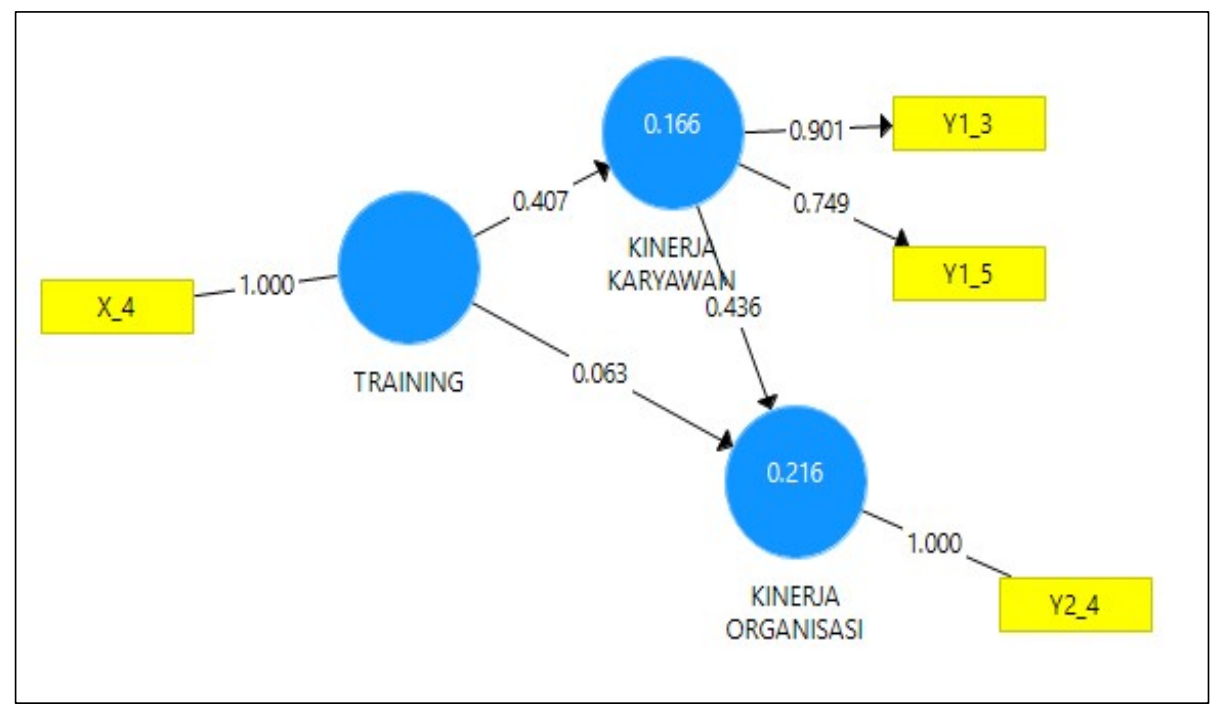

Gambar 2 Model SEM yang telah reliabel 
Jurnal Satyagraha

Vol. 03, No. 02, Agustus 2020 - Januari 2021

ISSN : 2620-6358

http://ejournal.universitasmahendradatta.ac.id/index.php/satyagraha

Tabel 2 Outer Loadings yang telah reliabel

\begin{tabular}{|c|c|c|c|}
\hline \multicolumn{4}{|c|}{ Outer Loadings } \\
\hline \multicolumn{4}{|l|}{ Matrix } \\
\hline & KINERJA KARY... & KINERJA ORGA... & TRAINING \\
\hline$X \_4$ & & & 1.000 \\
\hline Y1_3 & 0.901 & & \\
\hline Y1_5 & 0.749 & & \\
\hline$Y 2 \_4$ & & 1.000 & \\
\hline
\end{tabular}

(2) Discriminant Validity

Discriminant validity

indikator refleksif dapat

dilihat pada cross loading

antara indikator dengan konstruknya pada - PLS

Algorithm report discriminant validity cross loading, hasilnya sebagai tabel di bawah ini.

Tabel 3 Hasil Discriminant Validity

\begin{tabular}{|c|c|c|c|c|}
\hline \multicolumn{5}{|c|}{ Discriminant Validity } \\
\hline \multirow[t]{2}{*}{ Fo } & Fornell-Larcker Criteri... & \multicolumn{2}{|c|}{ Cross Loadings } & \multirow{2}{*}{$\begin{array}{l}\text { NING } \\
\text { NIN }\end{array}$} \\
\hline & KINERJA KARY... & KINERJA ORG... & TRAII & \\
\hline$x_{-} 4$ & 0.407 & 0.240 & & 1.000 \\
\hline Y1_3 & 0.901 & 0.422 & & .426 \\
\hline Y1_5 & 0.749 & 0.335 & & 0.214 \\
\hline Y2_4 & 0.461 & 1.000 & & 0.240 \\
\hline
\end{tabular}


Jurnal Satyagraha

Vol. 03, No. 02, Agustus 2020 - Januari 2021

ISSN : 2620-6358

http://ejournal.universitasmahendradatta.ac.id/index.php/satyagraha

Dari tabel di atas bahwa korelasi

konstruk :

(a) Kinerja Karyawan dengan indikatornya lebih tinggi

dibandingkan korelasi indikator X_4,

Y1_3, Y1_5 dengan konstruk

Kinerja Organisasi.

(b) Kinerja Organisasi dengan

indikatornya lebih tinggi

dibandingkan korelasi indikator

Y2_4 dengan konstruk Kinerja

Karyawan.

(c) Pelatihan (Training) dengan

indikatornya lebih tinggi

dibandingkan korelasi indikator X_4

dengan konstruk Kinerja Karyawan

dan Konerja Organisasi.

(3) Average Variance Extracted (AVE)
Metode lain untuk menilai discriminant validity adalah dengan membandingkan akar kuadrat dari Average Variance Extracted ( $\mathrm{AVE})$ untuk setiap konstruk dengan korelasi antara konstruk dengan konstruk lainnya dalam model. Model mempunyai discriminant validity yang cukup jika akar AVE untuk setiap konstruk lebih besar daripada korelasi antara konstruk dan konstruk lainnya.

Hasil Average Variance Extracted (AVE) sebagai berikut :

Tabel 4 Hasil AVE dari Smart PLS

\begin{tabular}{|c|c|}
\hline & Average Variance Extracted (AVE) \\
\hdashline KINERJA KARYAWAN & 0.686 \\
\hdashline KINERJA ORGANISASI & 1.000 \\
TRAINING & 1.000 \\
\hline
\end{tabular}


Jurnal Satyagraha

Vol. 03, No. 02, Agustus 2020 - Januari 2021

ISSN : 2620-6358

http://ejournal.universitasmahendradatta.ac.id/index.php/satyagraha

Tabel 5 Hasil AVE yang diolah

\begin{tabular}{|l|l|l|l|}
\hline & \multicolumn{1}{|c|}{$\begin{array}{c}\text { Kinerja } \\
\text { Karyawan }\end{array}$} & \multicolumn{1}{c|}{$\begin{array}{c}\text { Kinerja } \\
\text { Organisasi }\end{array}$} & \multicolumn{1}{|c|}{ Training } \\
\cline { 3 - 4 } & & \multicolumn{2}{|c|}{$\begin{array}{l}\text { Akar Kuadrat } \\
\text { AVE }\end{array}$} \\
\hline Kinerja Karyawan & 0.828 & $1.000 \leftarrow$ & $\downarrow$ \\
\hline Kinerja Organisasi & 0.678 & 0.489 & 1.000 \\
\hline Training & 0.637 & & \\
\hline
\end{tabular}

Setelah akar kuadrat dari konstruk Kinerja Organisasi dan Average Variance Extracted ( $\sqrt{\mathrm{AVE}}$ ) Training lebih besar dari konstruk untuk setiap konstruk dengan Kinerja Karyawan.

korelasi antara konstruk dengan Untuk mendapatkan latent konstruk lainnya dalam model, variable correlation pada PLS bahwa model mempunyai Algorithm report - pilih Laten discriminant validity yang cukup Variable Correlation dengan hasil hasil dari akar kuadrat AVE untuk serbagai berikut :

Tabel 6 Latent Variabel

\begin{tabular}{|c|c|c|c|c|}
\hline \multicolumn{5}{|l|}{ Latent Variable } \\
\hline \multirow[t]{2}{*}{ Latent Variable } & \multicolumn{3}{|c|}{ Latent Variable Correlations } & \multirow{2}{*}{\begin{tabular}{|l} 
Latent \\
TRAINING
\end{tabular}} \\
\hline & KIN & NERJA KARY... & KINERJA ORG... & \\
\hline $\begin{array}{l}\text { KINERJA KARY... } \\
\text { KINA. }\end{array}$ & & 1.000 & 0.461 & 0.407 \\
\hline KINERJA ORG... & & 0.461 & 1.000 & 0.240 \\
\hline TRAINING & & 0.407 & 0.240 & 1.000 \\
\hline
\end{tabular}

I Made Anom Arya Pering 
Jurnal Satyagraha

Vol. 03, No. 02, Agustus 2020 - Januari 2021

ISSN : 2620-6358

http://ejournal.universitasmahendradatta.ac.id/index.php/satyagraha

Untuk mendapat nilai validity $\quad-\quad$ Fornwll-Larcker discriminant validity pada PLS Criterium, hasil sebagai di bawah ini. Algorithm report pilih discriminant

Tabel 7 Discriminant Validity

\begin{tabular}{|c|c|c|c|c|c|c|}
\hline \multicolumn{7}{|c|}{ Discriminant Validity } \\
\hline \multirow[t]{2}{*}{ 暍 } & \multicolumn{2}{|c|}{ Fornell-Larcker Criteri..: } & \multicolumn{2}{|c|}{ Cross Loadings } & 㘣 & \multirow{2}{*}{$\begin{array}{c}\text { Heterotrait-Monot, } \\
\text { TRAINING }\end{array}$} \\
\hline & & KINERJA & KARY... & KINERJA ORC & GA... & \\
\hline & NERJA KARY... & & 0.828 & & & \\
\hline & NERJA ORGA... & & 0.461 & & .000 & \\
\hline & AINING & & 0.407 & & 240 & 1.000 \\
\hline
\end{tabular}

Dari tabel di atas dapat korelasi antara konstruk Pelatihan disimpulkan bahwa akar AVE (Training) dengan Kinerja Karyawan konstruk Pelatihan (Training) sebesar $(\sqrt{ } 0.407$ dan Kinerja sebesar 1.000 lebih tinggi daripada Organisasi $(\sqrt{ } 0,240)$ Begitu juga dengan akar AVE estimasi memenuhi kriteria konstruk Kinerja Organisasi sebesar discriminant validity.

1.000 lebih tinggi daripada korelasi Uji lainnya adalah menilai antara konstruk Kinerja Karyawan validitas dari konstruk dengan melihat sebesar $(\sqrt{ } 0.461)$. Jadi semua nilai AVE, dipersyaratkan model yang konstruk dalam model yang di 
Jurnal Satyagraha

Vol. 03, No. 02, Agustus 2020 - Januari 2021

ISSN : 2620-6358

http://ejournal.universitasmahendradatta.ac.id/index.php/satyagraha

baik kalau AVE masing-masing mengukur konstruk. Konstruk

konstruk nilainya lebih besar dari 0.50

Hasil output AVE menunjukkan

bahwa nilai AVE baik untuk konstruk

Kinerja Karyawan, Kinerja Organisasi,

dan Pelatihan (Training) memiliki nilai

AVE lebih besar dari 0.50

(4) Composite Reliability dan Cronbach Alpha

Disamping uji validitas konstruk, dilakukan juga uji reliabilitas konstruk yang diukur dengan dua kriteria yaitu composite reliability dan cronbach alpha dari blok indikator yang

Tabel 8 Construct Reliability and Validity dinyatakan reliabel jika nilai composite reliability maupun cronbach alpha di atas 0.70

Pada PLS Algorithm report dengan hasil sebagai di bawah ini.

\begin{tabular}{|c|c|c|c|c|c|c|}
\hline \multicolumn{7}{|c|}{ Construct Reliability and Validity } \\
\hline Matrix & 摸育 & Cronb & s Alpha & 拱钅 rho_A & 摸莘 & Composite Reliability \\
\hline & & & \multicolumn{2}{|c|}{ Cronbach's Alpha } & \multicolumn{2}{|c|}{ Composite Reliability } \\
\hline \multicolumn{3}{|c|}{ KINERJA KARYAWAN } & \multicolumn{3}{|c|}{0.558} & 0.813 \\
\hline \multicolumn{3}{|c|}{ KINERJA ORGANISASI } & \multicolumn{3}{|c|}{1.000} & 1.000 \\
\hline \multicolumn{3}{|l|}{ TRAINING } & \multicolumn{3}{|c|}{1.000} & 1.000 \\
\hline
\end{tabular}

Hasil output Composite atas 0.70 artinya konstruk tersebut reliability pada konstruk Kinerja adalah "reliabel". Sedangkan hasil Karyawan, Kinerja Organisasi, dan output Cronbach Alpha konstruk Pelatihan (Training) semua berada di Kinerja Karyawan dengan nilai 0.558 
Jurnal Satyagraha

Vol. 03, No. 02, Agustus 2020 - Januari 2021

ISSN : 2620-6358

http://ejournal.universitasmahendradatta.ac.id/index.php/satyagraha

berada di bawah 0.70 artinya goodness-fit model. Model pengaruh

konstruk Kinerja Karyawan "tidak Kinerja Karyawan terhadap Kinerja

reliabel". Cronbach Alpha pada Organisasi memberikan nilai R-

konstruk Kinerja Organisasi dan Square sebesar 0.166 yang dapat di

Konstruk Pelatihan (Training) interpretasikan bahwa variabelitas

dengan nilai di atas 0.70 artinya konstruk Kinerja Karyawan 16,6\%

konstruk tersebut adalah "reliabel". $\quad$ sedangkan $83,4 \%$ dijelaskan oleh

b. Pengukuran Model Struktural (Inner variabel lain diluar yang diteliti.

Model)

Pada PLS Algorithm report pilih R

a) Pengukuran terhadap model Square dan Square Adjusted sebagai struktural dilakukan dengan melihat berikut:

nilai R-Square yang merupakan uji

Tabel 9 R Square

\begin{tabular}{|c|c|c|c|c|}
\hline \multicolumn{5}{|l|}{ R Square } \\
\hline \multirow[t]{2}{*}{ Matrix } & 掉辛 R Square & 掉音 R Square & Adjusted & \\
\hline & & R Square & R Square & Adjus... \\
\hline \multicolumn{2}{|c|}{ KINERJA KARYAWAN } & 0.166 & & 0.140 \\
\hline \multicolumn{2}{|c|}{ KINERJA ORGANISASI } & 0.216 & & 0.167 \\
\hline
\end{tabular}

b) Uji yang kedua adalah melihat signifikansi $t$ statistik. Pada signifikansi dengan melihat nilai Algorithm Boostrapping report pilih koefisien parameter dan nilai 
Jurnal Satyagraha

Vol. 03, No. 02, Agustus 2020 - Januari 2021

ISSN : 2620-6358

http://ejournal.universitasmahendradatta.ac.id/index.php/satyagraha

Path Coefficients, hasil yang diperoleh pada Path Coefficients :

Tabel 10 Path Coefficients

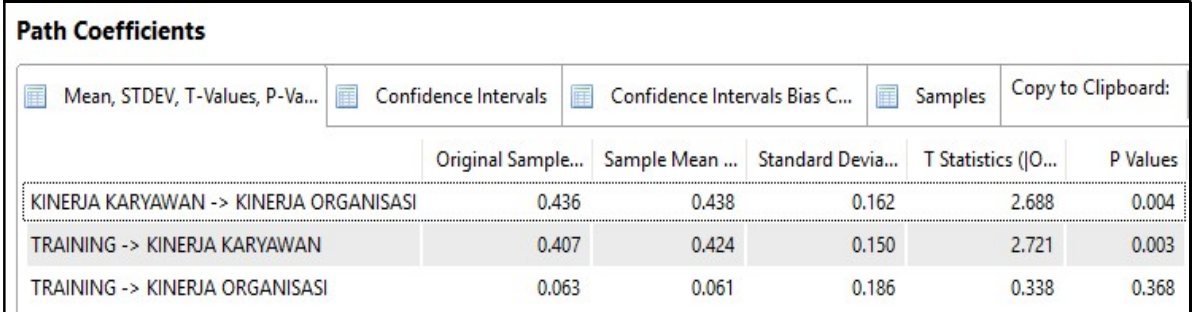

Interpretasi Path Coefficients :

Besarnya koefisien parameter 0.407

(a) Pengaruh Kinerja Karyawan yang berarti terdapat pengaruh

terhadap Kinerja Organisasi

Besarnya koefisien parameter 0.436

yang berarti terdapat pengaruh

positif Kinerja Karyawan terhadap

Kinerja Organisasi. Nilai t-statistik

sebesar 2.721 dan signifikansi (t-

tabel signifikansi $5 \%=1.96$ ) oleh

karena nilai t-statistik 2.721 lebih

besar $(>$ ) dari t-tabel 1.96 maka

Kinerja Karyawan berpengaruh

"signifikan" terhadap Kinerja

Organisasi.

(b) Pengaruh Pelatihan (Training)

terhadap Kinerja Karyawan positif Pelatihan (Training) terhadap

Kinerja Karyawan. Nilai t-statistik

sebesar 2.688 signifikansi (t-tabel

signifikansi $5 \%=1.96)$ oleh karena

nilai t-statistik 2.688 lebih besar (>)

dari t-tabel 1.96 maka Pelatihan

(Training) berpengaruh "signifikan"

terhadap Kinerja Karyawan.

(c) Pengaruh Pelatihan (Training)

terhadap Kinerja Organisasi

Besarnya koefisien parameter 0.063

yang berarti terdapat pengaruh

positif Pelatihan (Training) terhadap

Kinerja Karyawan. Nilai t-statistik

sebesar 0.338 signifikansi (t-tabel 
Jurnal Satyagraha

Vol. 03, No. 02, Agustus 2020 - Januari 2021

ISSN : 2620-6358

http://ejournal.universitasmahendradatta.ac.id/index.php/satyagraha

signifikansi $5 \%=1.96)$ oleh karena

nilai t-statistik 0.338 lebih kecil $(<)$

dari t-tabel 1.96 maka Pelatihan
(Training) "tidak signifikan"

berpengaruh langsung terhadap

Kinerja Organisasi.

\section{SIMPULAN DAN SARAN}

\section{Kesimpulan}

Kajian Analisis Jalur (Path

Analysis) pada Pengaruh atau

Dampak Pelatihan (Training)

terhadap Kinerja Karyawan dan

Kinerja Organisasi dengan

menggunakan SEM - Smart-PLS

versi 3.0 sebagai berikut :

1. Pengaruh Kinerja Karyawan

terhadap Kinerja Organisasi

Nilai t-statistik sebesar 2.721 dan signifikansi (t-tabel signifikansi 5\%

$=1.96)$ oleh karena nilai t-statistik

2.721 lebih besar $(>)$ dari t-tabel

1.96 maka Kinerja Karyawan

berpengaruh "signifikan" terhadap

Kinerja Organisasi.
2. Pengaruh Pelatihan (Training)

terhadap Kinerja Karyawan

Nilai t-statistik sebesar 2.688

signifikansi (t-tabel signifikansi 5\%

$=1.96)$ oleh karena nilai t-statistik

2.688 lebih besar $(>)$ dari t-tabel 1.96

maka Pelatihan (Training)

berpengaruh "signifikan" terhadap

Kinerja Karyawan.

3. Pengaruh Pelatihan (Training)

terhadap Kinerja Organisasi

Nilai t-statistik sebesar 0.338

signifikansi (t-tabel signifikansi $5 \%$

$=1.96)$ oleh karena nilai t-statistik

0.338 lebih kecil $(<)$ dari t-tabel 1.96

maka Pelatihan (Training) "tidak 
Jurnal Satyagraha

Vol. 03, No. 02, Agustus 2020 - Januari 2021

ISSN : 2620-6358

http://ejournal.universitasmahendradatta.ac.id/index.php/satyagraha

signifikan" berpengaruh langsung

terhadap Kinerja Organisasi.

\section{Saran}

Bahwa Structural Equation

Modeling (SEM) dengan Smart-PLS

\section{References}

[1] Ananda Sabil Hussein, SE., M.Com., Ph.D., 2015. Penelitian Bisnis dan Manajemen Menggunakan Partial Least Squares (PLS) dengan Smart PLS 3.0, Fakultas Ekbis Universitas Brawijaya, Malang.

[2] Dessler, Gary. 2009. Manajemen Sumber Daya Manusia. PT Indeks. Jakarta.

[3] Ghozali, Prof. Drs. H. Imam, M.Com., Ph.D.Ak., 2014. Partial Least Squares Konsep, Teknik dan Aplikasi menggunakan Program Smart PLS 3.0 untuk penelitian Empiris, Badan Penerbit Universitas Diponegoro, Semarang.

[4] Hasibuan, Malayu S.P. 2011. Manajemen Sumber Daya Manusia. PT Prenhallindo, Jakarta. agar dimasukkan dalam Satuan

Acara Pembelajaran (SAP) pada

mata kuliah Aplikasi Kuantitatif, agar para peneliti khususnya para mahasiswa dapat memahami dan menggunakan analisis SEM dengan software Smart-PLS.

[5] Mangkunegara, Anwar Prabu. 2007. Evaluasi Kerja Manajemen Sumber Daya Manusia. PT Refika Aditama. Bandung

[6] Mathis \& Jackson. 2006. Manajemen Sumber Daya Manusia. Salemba Empat. Jakarta.

[7] Noor, Dr. Juliansyah, SE., MM. 2015. Analisis Data Penelitian Ekonomi dan Manajemen. Grasindo. Jakarta.

[8] Pasolong, Harbani. 2010. Teori Administrasi Publik. Alfabeta, Bandung.

[9] Riduwan Dr. MBA., 2009. Pengantar Statistika untuk Penelitian Pendidikan, Sosial, Ekonomi, Komunikasi dan Bisnis. Alfabeta. Bandung.

[10] Sarwono, Jonathan. 2007. Analisis Jalur untuk Riset Bisnis dengan SPSS. Penerbit Andi, Yogyakarta. 
Jurnal Satyagraha

Vol. 03, No. 02, Agustus 2020 - Januari 2021

ISSN : 2620-6358

http://ejournal.universitasmahendradatta.ac.id/index.php/satyagraha

[11] Santoso, Singgih. 2018. Aplikasi SEM dengan AMOS. Elex Media Komputindo, Jakarta.

[12] Sinambela, Lijan. 2012. Kinerja Pegawai: Teori, Pengukuran dan Implikasi. Graha Ilmu. Yogyakarta.

[13] Sugiyono, Prof. Dr., 2014. Metode Penelitian Kuantitatif, Kualitatif dan $R \& D$, Alfabeta. Bandung.

[14] Sutrisno, Edi. 2009. Manajemen Sumber Daya Manusia. Kencana Prenada Media Group. Jakarta.

[15] Usman, Prof. Dr. Husaini M.Pd., MT., 2017. Metodologi Penelitian Sosial. Bumi Aksara. Bandung. 